\title{
REVIEW OF PROPERTIES, COMPOSITION AND DEFECTS OF DIFFERENT GLASSES WITH POTENTIAL USE FOR GAS HYDROGEN STORAGE SYSTEMS
}

\author{
Andrei RĂȚOI ${ }^{1}$, Corneliu MUNTEANU ${ }^{1,2^{*}}$, Bogdan ISTRATE$^{1}$, Dan ELIEZER $^{3 *}$ \\ ${ }^{1}$ Faculty of Mechanical Engineering, "Gheorghe Asachi” Technical University of Iasi, \\ Blvd. Prof. Dr. doc. Dimitrie Mangeron 61-63, Iasi 700050, Romania \\ ${ }^{2}$ Tech Sci Acad Romania, 26 Dacia Blvd, Bucharest 030167, Romania \\ ${ }^{3}$ Ben Gurion Univ Negev, Dept Mat Engn, 1 David Ben Gurion Blvd, IL-8410501 Beer Sheva, Israel
}

\begin{abstract}
The article reviews the research findings available on different types of glasses that presents potential use for high pressure gas hydrogen storage systems. An overview of the mechanical properties of different glasses, the influence of main constituents and the impact of defects to the strength of glass was presented. As part of this research, it can be concluded that the glass gets a significant improvement of tensile strength by reducing its dimensions to fibre sizes or capillaries due to reduced probability of defects presence.
\end{abstract}

Keywords: glasses, gas hydrogen storage, glass fibre, mechanical properties, composition, defects, review.

\section{Introduction}

Glass is a solid amorphous material that does not present a crystallin structure with a large usage both technological and aesthetical. The oldest type of glass discovered up to now is the silicate glass obtained from a chemical compound of silica, the main constituent of sand [1]. From structural point of view, at atomic scale, glass presents a random grouping of molecules, the most of them being oxygen ions linked together in a framework creating ions of boron, silicon or phosphor [2].

A glass made only from silica presents superior properties, but, unfortunately, due to the high temperatures needed during the production process, it becomes hard to be manufactured and expensive, so, from this reason, different framework modifiers ions as sodium, potassium or calcium are used to improve the process [2].

The article presents an overview of different types of glasses related to the most important mechanical properties that has an influence on the gravimetric and volumetric capacity of the hydrogen storage systems and additionally the impact of the defects to the strength of glass.

\section{Glass composition and properties}

The main glass constituents and their roles are as follows: 
Silica -is the main constituent element of glass. Due to hard and expensive manufacturing process of glass containing only silica, different alkaline materials and lime in adequate proportions needs to be included [2].

Sodium or potassium carbonate - it is included in adequate quantities in order to reduce the melting point of silica and to improve the viscosity [2].

Calcium oxide -it is introduced as chalk in order to increase the glass durability. To have a glass with increased brightness, lead oxide needs to be used instead of lime [2].

Manganese dioxide -is a component used in a certain proportion in order to ameliorate the colour of glass due to the presence of iron into the glass raw material [2].

Dyes -are used in order to obtain a certain colour for glass:

Table 1. Dyes used for glass production [2]

\begin{tabular}{cc}
\hline Color & Coloring substance \\
\hline Black & Cobalt, Nickel and Manganese Oxide \\
Green & Chromic Oxide \\
Red & Copper Oxide, Selenium \\
Purple & Manganese Dioxide \\
White & Cryolite, Tin Oxyde \\
Yellow & Cadmium Sulfate \\
\hline
\end{tabular}

By choosing a certain application for glass, different composition were identified as can be observed in the table below:

Table 2. Comparative study on the composition of glass in mass percentages [3]

\begin{tabular}{llccccc}
\hline & $\begin{array}{c}\text { Classic soda-lime- } \\
\text { silica glass } \\
\text { (windows glass) }\end{array}$ & $\begin{array}{c}\text { Laboratory and } \\
\text { baking glassware }\end{array}$ & $\begin{array}{c}\text { Optical } \\
\text { glass }\end{array}$ & $\begin{array}{c}\text { Silica } \\
\text { glass }\end{array}$ & $\begin{array}{c}\text { Primitive soda- } \\
\text { lime-silica glass }\end{array}$ \\
\hline Silica & $\mathrm{SiO}_{2}$ & $73,6 \%$ & $80,0 \%$ & $35,0 \%$ & $96,5 \%$ & $67,0 \%$ \\
Soda & $\mathrm{Na}_{2} \mathrm{O}$ & $16,0 \%$ & $4,0 \%$ & - & - & $18,0 \%$ \\
Lime & $\mathrm{CaO}$ & $5,2 \%$ & - & - & - & $8,0 \%$ \\
Potash & $\mathrm{K}_{2} \mathrm{O}$ & $0,6 \%$ & $0,4 \%$ & $7,2 \%$ & - & $1,0 \%$ \\
Magnesia & $\mathrm{MgO}$ & $3,6 \%$ & - & - & - & $1,0 \%$ \\
Alumina & $\mathrm{Al}_{2} \mathrm{O}_{3}$ & $1,0 \%$ & $2,0 \%$ & - & $0,5 \%$ & $2.5 \%$ \\
\hline
\end{tabular}

The most known types of glasses are the followings:

\section{Soda lime glass}

Sodium carbonate $\left(\mathrm{Na}_{2} \mathrm{CO}_{3}\right)$ is a frequent used additive introduced to lower the transition temperature of the glass. Lime $(\mathrm{CaO})$, a certain quantity of magnesium oxide $(\mathrm{MgO})$ and aluminum oxide $\left(\mathrm{Al}_{2} \mathrm{O}_{3}\right)$ are some common additives usually added to enhance the chemical durability. Soda-lime glass represents over $75 \%$ of the manufactured glass in the world and contains between 70 and $74 \%$ silica. As advantages, it is transparent, it is easy to be formed and perfect to be used for window glass and tableware. Disadvantages include the fact that it has a high thermal expansion and really low heat resistance. For these reasons, soda-lime glass is usually used for common day-by-day applications [1].

\section{Borosilicate glass}

Borosilicate glass (e.g., Duran) usually contains 5-13\% boron trioxide $\left(\mathrm{B}_{2} \mathrm{O}_{3}\right)$. In addition, borosilicate glasses have relatively low thermal expansion coefficients, thus, they are less subject to the stress generated by thermal expansion and therefore less exposed to crack occurrence due to thermal shock. They are commonly used for laboratory items, household utensils and headlights [1]. 


\section{Lead based glass}

To reduce the melting point, respectively the viscosity, lead oxide is added to the glass. Due to the high density, the refraction index of this type of glass is high leading to increased optical dispersion [4]. Beside this, lead oxide improves the solubility of metal oxides and represents an important element introduced in colored glass. On the other hand, compared to sodium glass, lead based glasses presents almost 100 times lower melt viscosity which allows easier removal of bubbles and an improved behavior for forming at lower temperatures [1].

\section{Aluminosilicate glass}

Aluminosilicate glass usually contains $5-10 \%$ alumina $\left(\mathrm{Al}_{2} \mathrm{O}_{3}\right)$. Compared to borosilicate glasses, this one is more difficult to be melt so harder to be formed in different shapes. Beside this, aluminosilicate glass is known for its excellent thermal resistance and durability [5].

\section{Ceramic glass}

This type of material contains both glass with a non-crystalline structure and ceramics with a crystalline structure, leading to superior chemical, thermal and biological properties [6]. However, the most important property of ceramic glass is the robustness against thermal shock, so it becomes extremely useful for cooking applications and industrial processes, even supporting repeated temperature variation cycles up to $1000{ }^{\circ} \mathrm{C}[1]$.

\section{Glass fiber}

It is obtained by pressing molten glass through a fine extruding shape and cutting afterwards at needed length [7]. It is generally used to produce composite materials by combining with plastic resins. In the form of fiberglass wool, it is used as an excellent thermal and sound insulating material [1].

\section{Phosphate glass}

Phosphate glass is a type of optical glass, which, unlike silicate glass with $\mathrm{SiO}_{2}$, forms a $\mathrm{P}_{2} \mathrm{O}_{5}$ substrate [8]. Because the bonds of phosphorus oxide are weaker than in the case of silica, the properties like chemical and abrasion resistance of this type of glass are getting lower than in case of silicate or borosilicate glasses. On the other hand, they have a high homogeneity and are suitable for optical applications [9].

When we are talking about gas hydrogen storage systems, the most important parameters are the gravimetric and volumetric capacity of the storage. The link between these two storage parameters and the materials used is the following: the material density has a direct link to the weight of the complete storage system, so to the gravimetric capacity, and the material tensile strength has link to the maximum pressure allowed in the storage that has an influence to the volumetric capacity.

In order to find the proper glass type to achieve high gravimetric and volumetric capacities, different glass types were compared to each other in terms of tensile strength and density[10-24]. The results of the comparison can be observed in (Fig. 1).

Based on the results presented in (Fig.1) we can observe that the lowest density can be found on borosilicate glass and D-glass fiber. From this point of view, this glass type will be preferred in terms of gravimetric storage capacity. From the strength point of view, it is completely clear that by having a fiber glass shape we can achieve strength from two to five times higher than a normal plate glass shape. In this case, to be able to withstand high pressures of hydrogen in the storage, the usage of glass capillaries seems to be the best approach. 


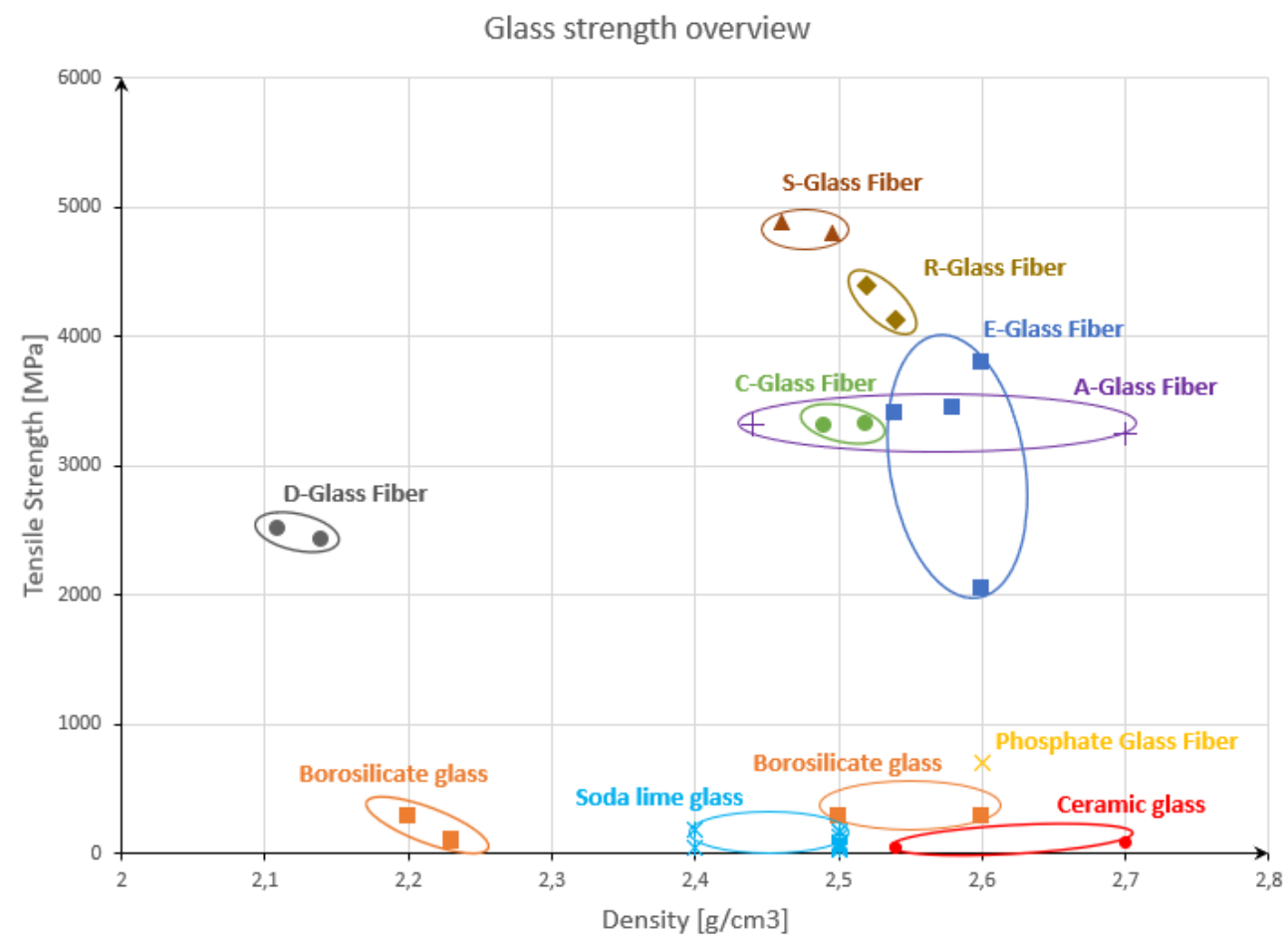

Fig. 1. Comparison between the density and tensile strength of different types of glass

\section{Glass defects}

Due to the manufacturing processes of the materials, various defects may occur. By definition, a defect is a physical, functional, or aesthetic attribute of a product or service that indicates that the product or service did not meet one of the desired specifications [25]. Based on the research done on the scientific literature, the following kind of defects were identified [26]:

a) Knots and striations - are glassy inclusions, i.e., glasses of different compositions in the base material. Nodes and striations are generally interconnected.

b) Crystals - are crystalline elements such as, for example, dendrites

c) Stones - describe compact inclusions. They can occur through crystallization of the glass itself, contamination or incomplete dissolution of the raw material

d) Metallic inclusions - appear either from metals used in the melting process, from refractory materials, contamination or from the different stages of glass processing

e) Bubbles - are empty spaces in glass filled with gas. These are the most common types of defects, most often containing gases such as oxygen, carbon dioxide, sulfur dioxide, argon, carbon monoxide or hydrogen.

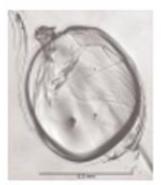

(a) knots

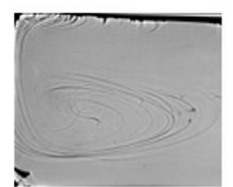

(b) striations

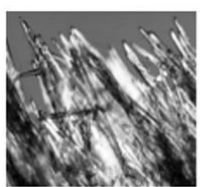

(c) crystals

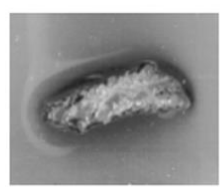

(d) stones

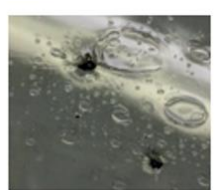

(e) inclusions

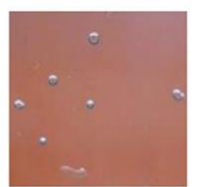

(f) bubbles

Fig. 2. Glass defects [26-29] 
They way that the glass defect influences negatively the strength of the glass material can be observed in the (Fig.3.).

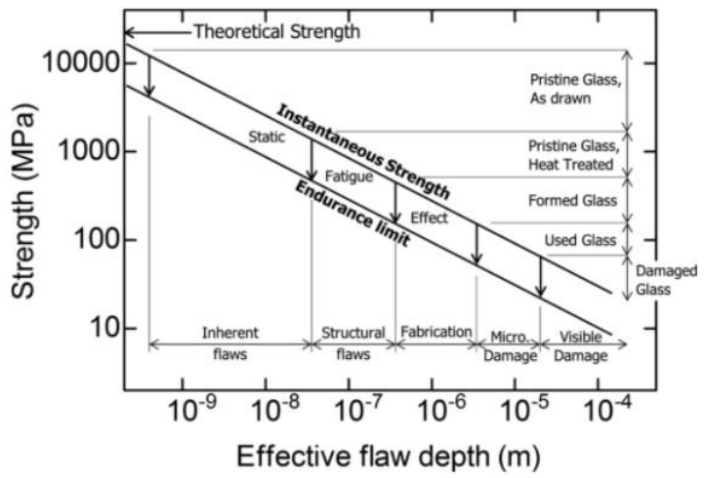

Fig. 3. Glass strength variation to flaw depth [30]

By analyzing the figure above, we can notice that as we move away from the primary state of the glass by applying various operations such as heat treatment, processing, use in different applications, its strength decreases. At the same time, the strength of the glass is also influenced by the size of the defects in the way that as the size of the defects increases, as expected, the strength will decrease.

\section{Conclusions}

Based on the existing scientific literature, different applications of the glass lead to the needs of different constituents with a certain weight percentage in order to improve the glass robustness.

After comparing different kind of glasses, in terms of high-pressure hydrogen storage systems, the best glass types to be used are the glass fibers due to their high strength properties.

\section{References}

[1] Kolb, K. E., Glass, Proceedings of Chemistry Explained, 7 july 2006.

[2] Britannica, Glass, Proceedings of Encyclopedia Britannica, 3 August 2021.

[3] Kurkjian C. R., Perspectives on the History of Glass Composition, Journal of American Ceramic Society, 81 (4), pp 795-813.

[4] M. Schwartz, Encyclopedia of Materials, Parts and Finishes (Second edition), CRC Press, 2002, pp. 352.

[5] Cormier L., Glasses: Aluminosilicates, Encyclopedia of Materials: Technical Ceramics and Glasses, Volume 2, 2021, pp 496-518.

[6] H. Wolfram, G.H. Beall, Glass Ceramic Technology, John Wilwy\& Sons, 2012, pp. 1-38.

[7] Varshneya, A.K., Industrial glass, Encyclopedia Britannica, 2016.

[8] M. Karabulut, E. Melnik, R. Stefan, GK Marasinghe, CS Ray, CR Kurkjian, DE Day, Mechanical and structural properties of phosphate glasses", Journal of Non-Crystalline Solids, 288 (1-3), 2001, pp 8-17.

[9] Kopp Glass, The properties of glass - ebook, Proceedings of Kopp Glass Company, 2016. [10] https://www.makeitfrom.com/material-properties/Soda-Lime-Float-Glass

[11] https://spectraglass.com/wp-content/uploads/2013/09/M010-Soda-Lime-Silica-Float.pdf 
[12] https://techhub.uk.saint-gobain-building-glass.com/sites/default/files/documentfiles/Glass \%20Fundamentals\%201B\%20-\%20The\%20Strength\%20of\%20Glass\%20-\%201 9-09-2018.pdf

[13] https://www.makeitfrom.com/material-properties/Borosilicate-Glass

[14] https://www.robuglas.com/fileadmin/dateien/Bilder/Service/Downloads/Technische_ Daten_im_Detail_eng/datasheet_vitrapor_e.pdf

[15] https://www.imetra.com/borosilicate-glass-material-properties/

[16] https://www.azom.com/properties.aspx?ArticleID=1441

[17] https://www.makeitfrom.com/material-properties/Machinable-Glass-Ceramic

[18]F.B. Betanzos, M. Gimeno-Fabra et. al. , Cyclic pressure on compressure-moulded bioresorbable phosphate glass fibre reinforced composites, Materials \& Design, 100, 2016, pp. 141-150.

[19] M. Derradji, J. Wang, W. Liu, 5 - Fiber - Reinforced Phthalonitrile Composites, Phthalonitrile Resins and Composites, 2018, pp. 241-294.

[20] D. Hull, T. Clyne, Fibres and matrices, Cambridge Solid State Science Series, Cambridge, 1996, pp 9-38.

[21] https://www.princelund.com/glass-fiber.html

[21] https://www.azom.com/properties.aspx?ArticleID=764

[22] http://www.matweb.com/search/DataSheet.aspx?MatGUID=d9c18047c49147a2a7c0b Obb1743e812

[23] https://jpscm.com/products/e-glass-s-glass/

[24] https://www.azom.com/properties.aspx?ArticleID=769

[25] https://www.dex.ro/defect

[26] H. Mueller, C. Strubel, K. Bange, Characterization and identification of local defects in glass, Scanning, 23, 2000, pp. 14-23.

[27] H. Gross, M. Hofmann, R. Jedamzik, P. Hartmann, S. Sinzinger, Measurement and Simulation of Striae in Optical Glass, Proceedings of SPIE - The International Society for Optical Engineering, june 2009.

[28] X. Li, Z.P. Fang, F.L. Ng, Inspection and Image Analysis of Nickel Sulphide Inclusions in Toughened Glass Panels, Proceedings of Ninth International Conference on Control, Automation, Robotics and Vision, ICARV 2006, 5-8 December 2006, Singapore.

[29] C.B. Carter, M.G. norton, Processing Glass and Glass-Ceramics, Ceramic Materials, 2012, pp 477-494.

[30] T. Rouxe, S. Yoshida, The fracture toughness of inorganic glasses, Journal of American Ceramic Society, 100, 2017, pp. 4374-4396.

Received: March 18, 2021

Accepted: May 02, 2021 